\title{
What Factors Impact Student - Content Interaction in Fully Online Courses
}

\author{
Dr. Dip Nandi \\ American International University- Bangladesh, Dhaka, 1213, Bangladesh \\ Email: dip.nandi@aiub.edu \\ Dr. Margaret Hamilton and Dr James Harland \\ RMIT University, Melbourne, Australia \\ Email: \{Margaret.hamilton, james.harland\}@rmit.edu.au
}

\begin{abstract}
The rapid advancement of fully online courses has made education accessible from "anywhere" and "anytime". One of the major success factors of online courses is effective student - content interaction - which defines how students interact with the content in the fully online learning environment. However, there appears to have been little research published about the relationship of content to course design and consequent outcomes for students. In this article, we report on our research on the investigation of factors that affect student - content interaction in fully online computing courses. We have conducted our research through surveys and used a grounded theoretic approach for data analysis. Our results identify the factors that are perceived by students as critical in ensuring effective student - content interaction in fully online computing courses.
\end{abstract}

Index Terms - Online learning, interaction, content management, learning environment, student centered, content structure.

\section{INTRODUCTION}

Popularity of Online education has increased rapidly over the recent years. Since the 1980s, there has been a substantial increase in the number of students studying part-time and through distance learning [1]. Every year, more universities are starting online programs [2, 3]. Institutional economics (e.g., lack of physical classroom space, need to attract students from beyond immediate geographic location and assumed economies of scale that can be achieved with more sections of a course and more students per section); and the demands of students who face a number of obstacles that make the on-campus format inconvenient are the main reasons for this increase [4]. As a result continuous research has been undertaken in this field on online education. A major focus has always been on the better use of technology to support learning, whereas the strategies for effective content management techniques to ensure productive student content interaction in fully online courses have not been adequately investigated [5].

Reference [6] reports significant disagreement that is present among researchers regarding the effect of
"Learning media" on "Student learning". The objective of this paper is to identify and explain the factors that impact interaction between fully online students and the content. Understanding of these factors can provide guidelines in setting up and managing effective interaction between students and content in fully online computing courses. This paper presents the findings of this research regarding the factors that impact the interactivity between online students and content in two fully online Computing courses. The data for this research was collected from two introductory Computing courses during one study period in 2011.

In particular this paper draws from existing literature about the different aspects of student - content interaction and discusses the finding of data analysis to answer the following question.

\section{BACKGROUND}

Interaction with content refers to students' engagement with instructional information and is the primary construct in predicting online satisfaction $[7,8]$. Studentcontent interaction may include reading informational texts, using study guides, watching videos, interacting with computer-based multimedia, and completing assignments and projects. Content interaction is critical for students to acquire new knowledge, skills and abilities which change their understandings and perspectives [6].

The processes of online teaching break into design perspective and method of delivery. Compared to regular classes, online courses impose stricter requirements for planning and design to be completed well in advance of the activity so as to avert problems that can arise with the technology systems such as Blackboard and Moodle [5]. Interaction is problematic for students when the systems' features do not function properly which may not impact the learning of in-class students but have a negative effect on the learning of distance students enrolled in fully online courses [9].

Universities use various content management systems to manage learning-related materials and student-learning processes which consist of a variety of technical capacities to support online learning [10]. Reference [8] 
state that a well-designed content management system can help enhance student - content interaction by providing various facilities such as study guides and links to other educational systems to better engage students in the learning content. Reference [11] state that a wellorganized and content-rich design can assist studentcontent interaction. Reference [12] state that lack of student - content interaction is a major weakness in current learning management systems. Reference [13] explain that since learning management systems initially emerged as document repositories, interactive learning support is not being reached as expected as it was not utilized up to full potential. Reference [9] state that course management systems should be flexible enough to provide better quality and student-centered education.

Researchers agree that it is challenging to accomplish the perfect student - content interaction [14]. Additionally, the role of the teacher changes to an organizer rather than information deliverer [15]. Identification of the factors that can provide guideline for "well-designed" and "well-organized" course management systems is essential for ensuring effective student-content interaction. There appears to have been little research published about the relationship of content to course design and consequent outcomes for students [5]. Fully online systems should provide a typically student-centred environment; hence research needs to be carried out of find out what critical criteria need to be considered for designing effective student - content interaction that suits the needs of the students.

\section{RESEARCH METHODOLOGY}

There is evidence for the value of accommodating student preferences in course design and further research is needed into how student preferences align with various aspects of course design [5]. This investigation enables us to identify and incorporate these student preferences.

In order to conduct the research two fully online introductory Computing courses were chosen from Open Universities Australia (www.open.edu.au). One of them is an Introduction to Programming course and the other is an Introduction to IT course.

Both courses were conducted in a fully online environment with no face-to-face classes. An overview of the courses is presented in Table 1. During this study period, one (same) instructor was in charge of both the courses. The instructor was assisted by a number of tutors. All the course materials were uploaded into Blackboard before the start of the study periods. Weekly synchronous chat sessions were organized by the instructor or tutors to discuss the study material for that week. These chat sessions were organized via Elluminate, a synchronous discussion tool with text, audio and video facilities which works in conjunction with Blackboard storing the recorded sessions.
Table 1. Overview of the fully online courses and their cohorts

\begin{tabular}{|l|l|l|}
\hline Course & $\begin{array}{l}\text { Introduction to } \\
\text { Information } \\
\text { Technology (IT) }\end{array}$ & $\begin{array}{l}\text { Introduction to } \\
\text { Programming (IP) }\end{array}$ \\
\hline Study Period & $\begin{array}{l}\text { June }- \text { August, } \\
2011\end{array}$ & $\begin{array}{l}\text { June - August } \\
2011\end{array}$ \\
\hline Number of Students & \multicolumn{1}{|c|}{250} & 180 \\
\hline $\begin{array}{l}\text { Number of Tutors } \\
\text { (apart from the } \\
\text { instructor) }\end{array}$ & \multicolumn{1}{|c|}{$83: 1$} & 2 \\
\hline $\begin{array}{l}\text { Ratio of Students to } \\
\text { Instructor (+Tutor) } \\
\text { (approx.) }\end{array}$ & Periodically (2) & P0:1 \\
\hline $\begin{array}{l}\text { Assignments } \\
\text { Released }\end{array}$ & $\begin{array}{l}\text { Periodically (3) } \\
\text { Technology, of } \\
\text { Business IT, } \\
\text { Indigenous Studies } \\
\text { and Accountancy }\end{array}$ & $\begin{array}{l}\text { Bachelor } \\
\text { Technology only }\end{array}$ \\
\hline $\begin{array}{l}\text { Students Enrolled } \\
\text { From }\end{array}$ & \multicolumn{1}{|c|}{ of } \\
\hline
\end{tabular}

Both the courses had online discussion forums where students were encouraged to participate and interact with each other. Several threads were created by the instructor in the study period to allow students to communicate via the online media. The threads were "Welcome and Introduction", "General Discussion", "Group Discussion forums", "Feedback" and "Assignment and Exam Discussion" were moderated by the instructor and the "Group Discussion" was also moderated by the tutors. On average, the instructor and tutors checked the discussion boards and responded once daily throughout the study period.

An important dimension of research is whether it is quantitative or qualitative for both data collection and analysis. Some researchers believe that qualitative and quantitative research can be effectively combined in the same research project $[16,17]$. By combining both methods, advantages of each methodology complement each other and make a stronger research design which results in valid and reliable findings [18]. Our research design was influenced by this concept of mixed method research and we designed a survey with both kinds of questions, see Appendix A. Hence we have applied a combination of quantitative and qualitative approaches with most emphasis on the qualitative approach.

With ethics approval, data was collected from the two cohorts of students through surveys throughout the study period starting from June 2011 till August 2011. Through qualitative data analysis of the survey responses, we attempted to uncover all the criteria which provided a clear representation regarding what the participants considered to be essential factors for setting up effective content management strategies.

The open ended responses in the survey were processed using the grounded theoretic approach [19] i.e. open, axial and selective coding [20]. All the responses were loaded into NVivo 8 software for investigation through open, axial and selective coding. The purpose of open coding was to identify the criteria which have emerged within the discussion forums. We identified around 50 criteria by analyzing the data at the end of the open coding phase. Each separate concept in the data was 
labeled and similar ideas were grouped together and relabeled. Following open coding, the next step was axial coding, where the aim was to assemble the coding categories into larger conceptual groupings [21]. Eight major categories emerged through data analysis. Each category consisted of a number of criterion and subcriterion. This process was repeated until no additional categories were identified and all the data had been analyzed.

The third and final coding step was selective coding. The data was re-examined, the prior coding and grouping was revisited and verified or changed as required. This set of emergent criteria is presented in the "Data analysis" section. This is the categorization which we have used to explain what factors need to be considered for effective student - content interaction. Apart from identifying the criteria, we also investigated how many times these criteria were mentioned by the students. This analysis assisted in quantifying student preferences in the two introductory computing courses.

We used triangulation and peer debriefing $[22,23]$ to ensure the credibility of the findings. The instructor was not a part of the investigation team, which eliminated any chance of bias in this analysis. One researcher analyzed the data, categorized the criteria, and presented the findings to co-researchers through peer debriefing. Inconsistencies and disagreement were discussed and managed through consensus reaching. A complete explanation of the courses and participants are presented to ensure the transferability of the study. The data analysis enabled the extraction of key and relevant information to the research and, as a result, the research question was explored based on the results ascertained.

\section{DATA ANALYSIS}

A total of 73 students responded to the survey with 46 from the Introduction to IT course and 27 from the Introduction to Programming course. Research shows that around $50-60 \%$ students never use the learning management system and hence not active at all in the discussion forums [24] making the effective survey response rate around $38 \%$ and $30 \%$ respectively for the IT and Programming courses which can be considered above average for fully online students [25]. This number of 73 is well above the suggested sample size for grounded theoretic approach [26, 27, 28]

Table 2. Overview of the survey respondents

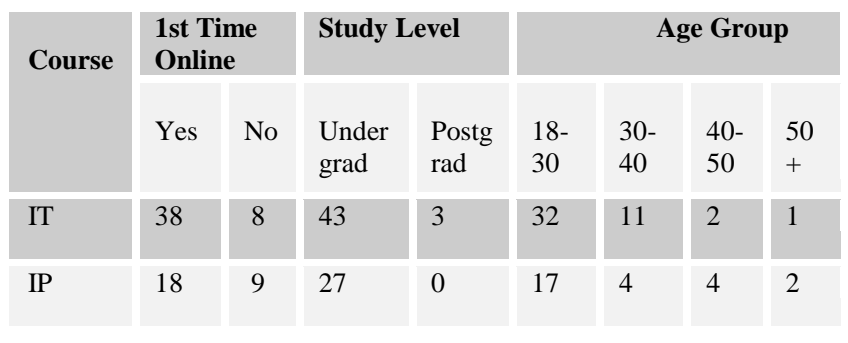

From Table 2 we can see that most of the students were undergraduates aged between 18 and 30 . As expected, these were the first fully online courses they had ever been enrolled into. Approximately 25 students out of 27 respondents in the Programming course used the online learning management system regularly throughout the course; whereas this number is 35 out of 46 respondents in the IT course.

Table 3. Criteria emergent from the survey and number of times they appeared

\begin{tabular}{|c|c|c|c|}
\hline Criteria & Sub Criteria & $\begin{array}{l}\text { Number of times in the survey } \\
\text { (IT) }\end{array}$ & $\begin{array}{l}\text { Number of times in the } \\
\text { survey (IP) }\end{array}$ \\
\hline \multirow[t]{4}{*}{ Structure } & Organization & 23 & 21 \\
\hline & Usability & 35 & 24 \\
\hline & Navigation & 21 & 24 \\
\hline & Information & 4 & 4 \\
\hline \multirow[t]{2}{*}{ Course Management } & Early Release & 30 & 7 \\
\hline & Periodic Release & 15 & 11 \\
\hline \multirow[t]{3}{*}{ Discussion Areas Accessed } & Assignment Forums & 14 & 14 \\
\hline & General Forums & 3 & 8 \\
\hline & Group Forums & 7 & 4 \\
\hline \multirow[t]{3}{*}{ Discussion Areas Posted } & Assignment Forums & 6 & 4 \\
\hline & General Forums & 8 & 12 \\
\hline & Group Forums & 4 & 1 \\
\hline \multirow{2}{*}{$\begin{array}{l}\text { Preferred Method for } \\
\text { Communication }\end{array}$} & Synchronous & 21 & 5 \\
\hline & Asynchronous & 15 & 13 \\
\hline \multirow[t]{2}{*}{ Type of Preferred Book } & E-Books & 15 & 11 \\
\hline & Paper Books & 5 & 2 \\
\hline \multicolumn{2}{|l|}{ Community Building } & 18 & 15 \\
\hline \multicolumn{2}{|l|}{ Task Distribution } & 17 & 10 \\
\hline
\end{tabular}


Table 3 presents the criteria that emerged from applying open, axial and selective coding to the survey responses. The number of times each criterion appeared from both Introduction to IT and Introduction to Programming courses has been charted. Eight main criteria were derived through data analyses which were considered as most important to ensure effective student content interaction in these fully online courses.

Survey respondents pointed out the flaws in the current content management system and also suggested ways though which effective student - content interaction can be ensured. Along with pointing out the flaws, students also placed their suggestions on how both content and content area should be managed. Through the analysis of flaws and suggestions put forward by the students, we have intended to identify a set of criteria and guidelines to ensure effective student - content interaction in fully only online courses. The findings from the survey analysis i.e. the criteria and sub-criteria are presented below.

\section{A. Structure}

Almost all the survey respondents emphasized the importance of proper content management structure. Poorly structured content management creates confusion and unsatisfactory learning experience.

We have divided this criterion into four categories; they are Organization, Usability, Navigation and Information. These sub-criteria are discussed below.

Organization: Organization of the content was termed as one of the most important factors in ensuring that students can have a smooth interaction with the content. This criterion was mentioned 23 and 21 times respectively in IT and IP. Most of the students felt that the current method of content organization is old, antiquated and should be revolutionized to make it more contemporary. They feel that current organization method makes it complicated and as a result creates difficulty into their efforts to learn.

Students suggested that organization of the content should be modernized and hence the examples from the social networking sites can be followed. Discussion threads should be properly managed and restricted to week by week and topic by topic. There should only be as many threads as required which should be organized in such a way that newly created threads or newly posted messages are easy to find.

Students mentioned that initially in the first few weeks of the courses, it was manageable to access the content through the current structure. After a few weeks into the course with huge numbers of new threads being created and new messages being posted, it got challenging for the students. Following the above mentioned steps should make it easier for the students to access and use the content throughout the courses.

Usability: Usability of the system to access the content was considered as the most important criteria for student - content interaction. Students mentioned about this criterion in their responses 35 times in IT and 24 times in IP. Students felt that the current system was not user friendly for accessing content and was one of the main reasons for their learning dissatisfaction. Students had to struggle to cope with the system to access almost every bit of content in the courses. This phenomenon of dissatisfaction was evident with all the IT students, while few of the IP students found the system to be user friendly.

Students suggested some features to improve the usability which were again mainly influenced by the social networking sites. Suggestions included using thread subscription, adding features such as notifications when their queries get responded, less number of threads, easier way to create and respond to quires in threads and flexible way to download content.

Adding the above mentioned features would make the system more user-friendly and hence students will be able to access content with less difficulty.

Navigation: Navigation refers to browsing through the learning management system in order to access the different content in the courses. Survey respondents pointed out to this criterion as very important while designing student - content interaction. This criterion was mentioned on 21 instances by IT students and 24 instances by IP students. Students felt that the navigation through the system to access content was not easy to handle and hence they struggled to browse through content. Students mainly went through the different threads and downloaded recorded tutorial sessions and offline study material. It took time for them to get familiarized with the system because of the distribution of links and tabs within the environment.

Students suggested that links can merged together to improve the distribution of links and tabs within the environment. An overhaul of the system is suggested with less number of links and tabs to browse through which should improve the navigation experience of the students.

Information: Students mentioned that there were lack of information regarding the use of different links, tabs and threads to access the content. Because of the lack of proper information, it took a while for the students to access the content and as a result fell behind on their study. This criterion was mentioned 4 times by students from both the courses. There were two types of information termed as important by the students; one was related to how to solve assignments such as what are the different criteria to solve in the assignment, how to handle specific issues, which concept to use and which not to and how to submit solved assignments. The other was related to navigation such as which link does what, what information can be found under what tab and how to find out about course administrative issues.

Students suggested that more clearly customized information is required for a better learning experience. Threads can be marked up by the instructors with information about their functionality and separate tutorial sessions can be arranged to provide students information about navigating and accessing the content.

Administrative guidelines and information can be placed in separate threads and pointed out clearly so that 
students can access it easily throughout the duration of the courses. As fully online students, their only media of accessing information is via the learning management system; hence detailed information should be provided to them in a structured manner.

\section{B. Course Management}

The way courses are managed has a strong impact on student content interaction. The main two factors that impact course management are the assessment and course notes and when to release them. Around $65 \%$ of the survey respondents in the IT course voted for early release whereas this number is only $26 \%$ for IP students. Most IP students (around 41\%) wanted the assignments to be released periodically and not early. These differences are discussed below.

Assessment: Most of IT students (65\%) and few IP students $(26 \%)$ felt that assignments should be released early in the course altogether. Students felt that releasing the assignments early, provides them with the opportunity to start working with them form the very beginning. It gives them enough time to plan their workload ahead as most of the fully online students have full time work and family commitments to take care.

On the contrary most of the IP students $(41 \%)$ felt than assignments should be released periodically. It allows them to learn the concepts first and then attempt the assignments. It also prevents them from rushing to assignments before going through the study material and has better understanding of what is expected in the assignment.

Course Notes: It was anonymously agreed that all course notes should be released altogether early in the course. This would allow students to self-pace their study and plan for the semester well in advance along with their work and family commitments. Clear directions are expected from the instructors on what to cover in which week and when assessments are due to handed. No survey respondent was in favour of periodical release of course material.

\section{Areas Accessed}

The mostly accessed discussion areas were the assignment forums in both the courses. Almost 30\% students in the IT course and $52 \%$ in the IP course responded that they mainly access the assignment forums as assignment related questions were discussed there. It allowed them to clarify the requirements for the assignments and get directions on solving the problems.

Only $7 \%$ students in the IT course and $30 \%$ in the IP course mainly accessed the general discussion forums. Reasons for accessing these forums include; able to discuss with all the students in the course, greater student participation in these forums and able to discuss general concepts and queries.

Around $15 \%$ students in both the courses accessed the group discussion forums regularly. These forums allowed them to discuss weekly study materials within a small group and the tutors. This analysis provides us with a clear view about discussion areas that are most accessed by students and the reasons for doing so.

\section{Areas Posted}

Unlike assignment forums which see most number of accesses, general discussion forum saw most number of posts from the students. Around $17 \%$ students in the IT course and $44 \%$ in the IP course responded that they preferred to participate and post mostly in the general discussion forum as it was accessible by all the students in the courses. Hence questions were responded quickly and directly unlike the assignment forums, where direct answers are no permitted.

Around $13 \%$ and $15 \%$ students in the IT and the IP course respectively thought that posting in the assignment forums are more advantageous. It allows them to ask questions about assignment criteria and guidelines. Very few students in both courses mentioned that they post in the group forum to discuss weekly study materials. These forums were created to discuss in small groups and were not popular with the students.

\section{E. Proffered Method Of Communication}

IP students (48\%) mostly preferred to use asynchronous for interaction while learning the content. This number was around $33 \%$ for IT students. Students mentioned that asynchronous communication allowed them time before asking responding to questions and had better student participation.

On the contrary, more IT students $(46 \%)$ than IP students $(19 \%)$ preferred to use synchronous communication. The benefits included; instant question and answer though text chat and problem solving through audio and video demonstration.

Students also suggested that, smaller groups should be made for synchronous communication sessions as it gets crowed and all queries cannot be responded among confusion.

\section{DISCUSSION}

Through data analysis, we have uncovered that, the most important criteria for effective student - content interaction is the structure of the content management system. Designing an appropriately structured content management system provides the students with the opportunity to browse and interact with the content of the courses. The four sub-criteria that came of data analysis under the main criterion structure are: Organization, Usability, Navigation and Information. A simple organizational content management structure which is effortlessly useable by the students, easy to browse through the online content and contains substantial amount of information about the system should ensure effective student - content interaction for fully online students.

Students pointed out that the current content organization is confusing; not user friendly; not easy to navigate through content and not enough information is provided. Reference [29] found out that academic web 
page containing more than three levels confuses students and students prefer a linear style for browsing web pages.

Students in this study suggested that the content management system should be modernized and made simpler. Required threads should be orderly created and managed, subscription facility should be added, notifications should be provided and there should be information about which link and tabs provide what functionality. The design patterns of the social networking sites such as Facebook were mentioned as examples of worthy structures. Integrating the design patters from such social networking sites into learning and content management system could be beneficial to students. The inclusion of the design and social approaches of the freely available social networking sites and web 2.0 technologies to science education have positive impact on learning [22, 30]. Ensuring the guidelines derived from this research should provide the students with a flexible, personalized and hence satisfactory learning experience which is critical for success in fully online computing courses.

The timing of assignment and course note release impacts student interaction with the content. This research has shown contradictory opinions among students about the timing of assignment releases. Most of the IT students preferred to have the assignment released early. The argument was that it allows fully online students with work and family commitments to plan their study requirements ahead. On the contrary more Programming students wanted the assignments to be released periodically as it would provide them with the opportunity to learn the concepts more thoroughly before attempting the assignments. As students with different styles interact with content in different ways [5], educators should take into consideration the course content and student cohort before implementing their strategy for assignments.

References [31] suggest that academic performance of the students is influenced by the number of accesses and posts. We found that students mostly accessed the assignment forum to find information, clarifications and hints about assignments. On the contrary, students mostly posted in the general discussion forums which were accessible to all the students. It indicates that students liked to participate in forums which are populated and vibrantly participated. The issue of task distribution among instructors and tutors is also dependent on access and participation as educators need to decide on how to distribute task [22]. Findings show that students have a goal based learning strategy where they concentrate more on assignments rather than leaning and discussing the study material first.

There were contradictory opinions among students regarding the choice for the preferred method of communication. The difference of opinion can be explained by the difference in course content [24]. IT students can get more benefits from synchronous communications as general information technology related topics can be discussed and straightforward answers to queries can be provided. Systematic and logical explanation is required in the Programming course, to respond to and analyze codes and it requires more time. Hence Programming students benefit more from asynchronous communication where they can get time to think and analyze.

Students anonymously agreed upon that e-books should be provided which suits the fully online mode of instruction and a learning community is important in achieving the success. Benefits for e-books include easily accessible, can be loaded into portable devices and hence remotely available. As a result students can have greater control over when and where learning takes place in the midst of work and family commitments [32]. Students suggested that he "Welcome and Introduction" or similar threads should be set up within groups which allows communication to be within small number of students. These results support the findings by reference [6] that that systematically designed interactive media can enhance interaction and learning.

\section{CONCLUSION}

E-learning concept follows the constructivism theory which states that knowledge must be constructed by the learner and cannot directly be supplied by the teacher [33]. Hence proper interaction with the content becomes essential. In this research, we have investigated the factors that impact student - content interaction in fully online courses. A number of key criteria emerged along with a visualization of the preference of fully online students. Results of data analysis show that there are eight criteria that need to be taken into account by the educators. They are: structure, course management, discussion areas frequently accessed and participated, preferred method for interaction, type of preferred book, community building and task distribution. It emerged from data analysis that properly organized structure, a usable system, clear and flexible navigation and adequate information about the content management assists students in effectively interacting with the online content. Students suggested a number of measures that would improve the overall structure of the content management system.

Data analysis also revealed the preference of the students in regards to timing of assignment releases, method of communication, type of books and also the reasons behind such predilection. Our research has revealed the set of criteria for designing effective content management strategies. The applicability of each and every criterion depends on the course content and student cohort.

Future research can be benefitted by applying these set of criteria into different online courses from diverse disciplines and investigating the implications. The applicability of these criteria can also be investigated into online professional training courses and the difference could be analyzed.

APPENDIX A 
Survey Questionnaire:

- Is this the first course where you are participating in online forums?

- Are you a postgraduate student or undergraduate student?

- What is your age level? i.e. within $18-30$ or $30-40$ or $40-50$ or $50+$ ?

- Was the setting and structure of the online learning management system (Blackboard) easy to follow? Why/Why not?

- Do/Did you regularly use the learning management system (Blackboard)? Why/Why not?

- Were the discussion threads easy to navigate through? Why/Why not?

- Do you think students should be divided in groups for better interaction? Why/Why not?

- Do you think all the course notes should be released early in the course or periodically? Why/Why not?

- Do you think assignments should be released early in the course or periodically? Why/Why not?

- Do you think it will be easier to follow assignment threads inside group discussion forums? Why/Why not?

- Do you think the "Welcome and Introduction" thread was enough to create a community of students? Why/Why not?

- Which forums within blackboard do/did you access most and why/Why not?

- In which forum within blackboard do/did you post most and why/Why not?

- Which media did you find most effective? Elluminate or Group discussion forum or General discussion forum? Why?

- Do you think the assignment threads should by handled by the tutors? Why/Why not?

- Do you think there should be E-books, available in Blackboard? Why/Why not?

- Do you have any suggestions regarding how the course content and discussion threads should be managed?

- Do you think there should be more information regarding which thread does what? If yes, what type of Information?

\section{REFERENCES}

[1] Tanaka, Y. (2005) 'Invited Workshop on Dissemination of Elearning Technologies and Applications: Memetic Approach to the Dissemination of Elearning Objects', Proceedings of the 4th International Symposium on Information and Communication Technologies WISICT '05, Dublin: Trinity College.

[2] Allen, I \& Seaman, J. (2005) 'Growing by degrees: Online education in the United States', 2005, Report sponsored by The Sloan Consortium.

[3] Waits, T, Lewis, L \& Greene, B. (2003) 'Distance education at degree-granting postsecondary institutions: 2000-2001', Washington, DC: U.S. Department of Education, National Center for Education Statistics, [NCES 2003-017]. Retrieved on June 1, 2012 from http://nces.ed.gov/pubsearch/pubsinfo.asp?pubid=200301 7.

[4] Ludwig-Hardman, S. \& Dunlap, J. (2003) 'Student support services for online students: Scaffolding for success', The International Review of Research in Open and Distance Learning, vol.4, no. 1, Retrieved October 15 , 2011, from http://www. irrodl.org/index.php/irrodl/article/view/131/211.

[5] Wilson, J \& Albion, P. (2009) 'Interaction, student styles, and content in online courses: implications for teacher preparation', In: Maddux, Cleborne, (ed.) Research highlights in technology and teacher education 2009, Society for Information Technology \& Teacher Education (SITE) / Association for the Advancement of Computing in Education (AACE), Chesapeake, VA, pp. 347-354. ISBN 1-880094-74-6.

[6] Lou, Y., Bernard, R. M. \& Abrami, P. C. (2006) 'Media and Pedagogy in Undergraduate Distance education: A Theory-Based Meta-Analysis of Empirical Literature', Educational Technology Research and Development, Vol. 54, No. 2, p. 141-176.

[7] Strachota, E. (2006) 'The Use of Survey Research to Measure Student Satisfaction in Online Courses, Midwest Research-to-Practice', Conference in Adult, Continuing, and Community Education, University of Missouri-St. Louis, MO, October 4-6, 2006.

[8] Chou, C., Peng, H. \& Chang, C. (2010) 'The technical framework of interactive functions for coursemanagement systems: Students' perceptions, uses, and evaluations', Computers \& Education. vol. 55 (2010), pp. 1004-1017.

[9] Vovides, Y., Sanchez-Alonso, S., Mitropoulou, V. \& Nickmans. G. (2007) 'The use of e-learning course management systems to support learning strategies and to improve self-regulated learning', Educational Research Review, vol. 2 pp. 64-74.

[10] Malikowski, S. R. (2008) 'Factors related to breadth of use in course management systems', The Internet and Higher Education, vol. 11, no. 2, pp. 81-86.

[11] Chang, S. H. \& Smith, R. A. (2008) 'Effectiveness of Personal Interaction in a Learner-Centered Paradigm Distance Education Class Based on Student Satisfaction' Journal of Research on Technology in Education, v40 n4 p407-426.

[12] Yasar, O. \& Adiguzela. T. (2010) 'A working successor of learning management systems: SLOODLE', Procedia Social and Behavioral Sciences, 2 (2010), pp. 5682-5685.

[13] Kemp, J. \& Livingstone, D. (2006) 'Putting a Second Life "Metaverse" Skin on Learning Management Systems, Proceedings of the Second Life Education Workshop at the Second Life Community Convention, San Francisco, pp. 13-18.

[14] Dunlap, J. C., Sobel, D. \& Sands. D. I. (2007) 'Supporting students' cognitive processing in online courses: Designing for Deep and Meaningful Student-to-Content Interactions', TechTrends, July/August 2007, vol. 51, no. 4.Authors (2012).

[15] Dominic, M., Anthony, B. \& Francis, S. (2015). 'A Framework to Formulate Adaptivity for Adaptive eLearning System Using User Response Theory' I.J. Modern Education and Computer Science, 2015, 1, 23-30 Published Online January 2015 in MECS (http://www.mecs-press.org/) DOI: 10.5815/ijmecs.2015.01.04 Copyright (C) 2015.

[16] Strauss, A.L. \& Corbin, J.M. (1990) 'Basics of qualitative research: grounded theory procedures and techniques, Sage Publications, Newbury Park, CA, USA. 
[17] Patton, M. Q. (1990) 'Qualitative evaluation and research methods, (2nd ed.), Newbury Park. CA: Sage publications, Inc.

[18] Laws, K \& McLeod, R. (2004) 'Case study and grounded theory: Sharing some alternative qualitative research methodologies with systems professionals', Proceedings of the 22nd International Conference, 25-29th July, Systems Dynamic Society.

[19] Strauss, A. L. and Corbin, J. M. (1998). Basics of qualitative research: techniques and procedures for developing grounded theory, 2nd ed, Sage Publications, Thousand Oaks, CA, USA.

[20] Neuman, W. L. (2006). Social research methods: Qualitative and quantitative approaches, 6th Ed.

[21] Glaser, B. G. \& Strauss, A. L. (1967). The discovery of grounded theory. Aldine, New York Xx.

[22] Nandi, D., Hamilton, M. \& Harland, J. (2012). Evaluating the quality of interaction in asynchronous discussion forums in fully online courses, Distance Education, 33:1, 5-30.

[23] Baran, E. \& Correia, A. (2009) 'Student-led facilitation strategies in online discussions', Distance Education, vol. 30, pp. 339-361.

[24] Nandi, D., Hamilton, M., Harland, J. and Warburton, G. (2011). How Active are Students in Online Discussion Forums?. In Proc. Australasian Computing Education Conference (ACE 2011), Perth, Australia. CRPIT, 114. John Hamer and Michael de Raadt Eds., ACS. 125-134.

[25] Sax, L., Gilmartin, S., and Bryant, A. (2003). Assessing response rates and non-response bias in web and paper surveys. Research in Higher Education, 44(4), 409 - 432.

[26] Mason, M. (2010) 'Sample Size and Saturation in $\mathrm{PhD}$ Studies Using Qualitative Interviews', Forum Qualitative Sozialforschung / Forum: Qualitative Social Research, vol. 11, no. 3, Art. 8, http://nbn-resolving.de/urn:nbn:de:0114fqs100387.

[27] Creswell, J. (1998) Qualitative inquiry and research design: Choosing among five traditions, Thousand Oaks, CA: Sage.

[28] Morse, J. M. (1994) 'Designing funded qualitative research', In Norman K. Denzin \& Yvonna S. Lincoln (Eds.), Handbook of qualitative research (2nd ed., pp. 220-235), Thousand Oaks, CA: Sage.

[29] Chen, C. Y., Pedersen, S. \& Murphy, K. L. (2011) 'Learners' perceived information overload in online learning via computer-mediated communication', Research in Learning Technology, vol. 19, no. 2, pp. 101116.

[30] Badge, J. L., Saunders, N. F. W. \& Cann, A. J. (2012) 'Beyond marks: new tools to visualise student engagement via social networks', Research in Learning Technology 2012, 20: $16283 \quad$ - DOI: 10.3402/rlt.v20i0/16283.

[31] Crampton, A., Ragusa A. T. \& Cavanagh, H. (2012) 'Cross-discipline investigation of the relationship between academic performance and online resource access by distance education students', Research in Learning Technology, 2012, 20: 14430 - DOI: 10.3402/rlt.v20i0/14430.
[32] Nie, M., Armellini, A., Witthaus G. \& Barklamb. K. (2011) 'How do e-book readers enhance learning opportunities for distance work-based learners?', Research in Learning Technology, vol. 19, no. 1, pp. 1938.

[33] Gilakjani, A. P., Leong, L. M., Ismail, H, N. (2013). 'Teachers' Use of Technology and Constructivism'. I.J.Modern Education and Computer Science, 2013, 4, 4963 Published Online May 2013 in MECS (http://www.mecs-press.org/) DOI:10.5815/ijmecs.2013.04.07 Copyright @ 2013.

\section{Authors' Profiles}



Dr. Dip Nandi has completed his $\mathrm{PhD}$ in Computer Science from the School of Computer Science and Information Technoly at RMIT University, Melbourne, Australia. His research interest includes Software Engineering, Management Information Systems, E-learning etc.

$\mathrm{He}$ is currently working as an Assistant Professor and Head of Undergraduate Program in the Department of Computer Science in American International University- Bangladesh.

Dr. Nandi can be contacted at dip.nandi@ aiub.edu.

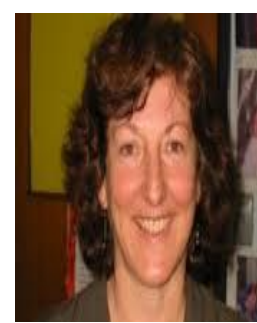

Dr. Margaret Hamilton is working as an Associate Professor in the School of Computer Science and Information Technology in RMIT University, Melbourne, Australia. Her research interest includes Software Engineering, Data Mining, E-learning etc.

Dr. Hamilton can be contacted at margaret.hamilton@rmit.edu.au.

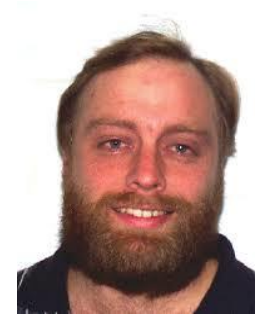

Dr. James Harland is working as an Associate Professor in the School of Computer Science and Information Technology in RMIT University, Melbourne, Australia. His research interest includes Computing Theory, Logic Programming, E-learning etc. Dr. Harland can be contacted at james.harland@rmit.edu.au

How to cite this paper: Dip Nandi, Margaret Hamilton, James Harland,"What Factors Impact Student - Content Interaction in Fully Online Courses", IJMECS, vol.7, no.7, pp.28-35, 2015.DOI: 10.5815/ijmecs.2015.07.04 